\title{
Quantifying digital ulcers in systemic sclerosis: reliability of digital planimetry in measuring lesion size
}

DOI:

10.1002/acr.23300

\section{Document Version}

Accepted author manuscript

Link to publication record in Manchester Research Explorer

\section{Citation for published version (APA):}

Simpson, V., Hughes, M., Wilkinson, J., Herrick, A., \& Dinsdale, G. (2018). Quantifying digital ulcers in systemic sclerosis: reliability of digital planimetry in measuring lesion size. Arthritis Care \& Research, 70(3), 486-490. https://doi.org/10.1002/acr.23300

\section{Published in:}

Arthritis Care \& Research

\section{Citing this paper}

Please note that where the full-text provided on Manchester Research Explorer is the Author Accepted Manuscript or Proof version this may differ from the final Published version. If citing, it is advised that you check and use the publisher's definitive version.

\section{General rights}

Copyright and moral rights for the publications made accessible in the Research Explorer are retained by the authors and/or other copyright owners and it is a condition of accessing publications that users recognise and abide by the legal requirements associated with these rights.

\section{Takedown policy}

If you believe that this document breaches copyright please refer to the University of Manchester's Takedown Procedures [http://man.ac.uk/04Y6Bo] or contact uml.scholarlycommunications@manchester.ac.uk providing relevant details, so we can investigate your claim.

\section{OPEN ACCESS}




\title{
Quantifying digital ulcers in systemic sclerosis: reliability of digital planimetry
}

in measuring lesion size

\author{
V. Simpson ${ }^{1}$, BSc MBChB, M. Hughes ${ }^{1}$, MRCP PhD, J. Wilkinson ${ }^{2}$, MSc, A. L. \\ Herrick, $\mathrm{MD}^{1,3}$, G. Dinsdale, $\mathrm{PhD}^{1}$
}

1. Division of Musculoskeletal \& Dermatological Sciences, University of Manchester, Salford Royal NHS Foundation Trust, Manchester Academic Health Science Centre, Manchester, UK.

2. Centre for Biostatistics, School of Health Sciences, Faculty of Biology, Medicine and Health, Manchester Academic Health Science Centre, University of Manchester, Manchester, M13 9PL, UK

3. NIHR Manchester Musculoskeletal Biomedical Research Unit, Central Manchester NHS Foundation Trust, Manchester Academic Health Science Centre, Manchester, UK

Corresponding author: Dr Graham Dinsdale, C214 Clinical Sciences Building, Salford Royal Hospital, Stott Lane, Salford, M6 8HD, UK. Email: graham.dinsdale@manchester.ac.uk. Telephone: (+44) 1612062935.

Running head: Ulcer planimetry in systemic sclerosis

Funding source: None

This article has been accepted for publication and undergone full peer review but has not been through the copyediting, typesetting, pagination and proofreading process which may lead to differences between this version and the Version of Record. Please cite this article as an 'Accepted Article', doi: 10.1002/acr.23300 (C) 2017 American College of Rheumatology

Received: J an 30, 2017; Revised: Apr 12, 2017; Accepted: J un 01, 2017 


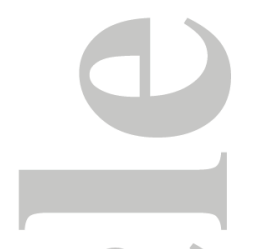

Conflicts of interest: None
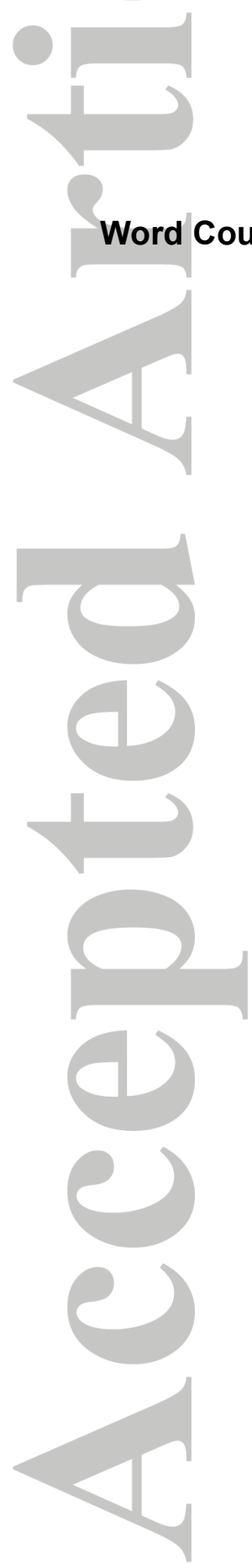

John Wiley \& Sons, Inc.

This article is protected by copyright. All rights reserved. 


\section{Abstract}

\section{Objective}

Digital ulcers (DUs) are a major problem in patients with systemic sclerosis (SSc), causing severe pain, and impairment of hand function. In addition, DUs heal slowly and sometimes become infected, which can lead to gangrene and necessitate amputation, without appropriate intervention. A reliable, objective method for assessing DU healing or progression is needed in both clinical and research arenas. The objectives were: (1) to compare two digital planimetry methods of DU area measurement (ellipse and free hand region-of-interest [ROI]) applied to photographs of DUs, and (2) to assess reliability of photographic calibration and the two area measurement methods.

\section{Methods}

107 DUs from 36 patients with SSc-spectrum disease were photographed. Three raters assessed the photographs. Custom software allowed raters to calibrate photograph dimensions, and draw ellipse/free-hand ROls. Shapes/dimensions for ROls were saved for further analysis.

\section{Results}

Calibration (single rater, 5 repeats/image) produced an intra-class correlation coefficient (intra-rater reliability) of 0.99 . Mean (SD) areas of DUs assessed using ellipse and free-hand ROls were $18.7(20.2) \mathrm{mm}^{2}$ and $17.6(19.3) \mathrm{mm}^{2}$, respectively. Intra- and inter-rater reliability of the ellipse ROI was 0.97 and 0.77 , respectively. For the free hand ROI, the intra- and inter-rater reliability was 0.98 and 0.76 .

\section{Conclusion}


This study shows digital planimetry methods applied to SSc-related DUs can be extremely reliable. Further work is now needed to move towards applying these as outcome measures for clinical trials, and in clinical settings.

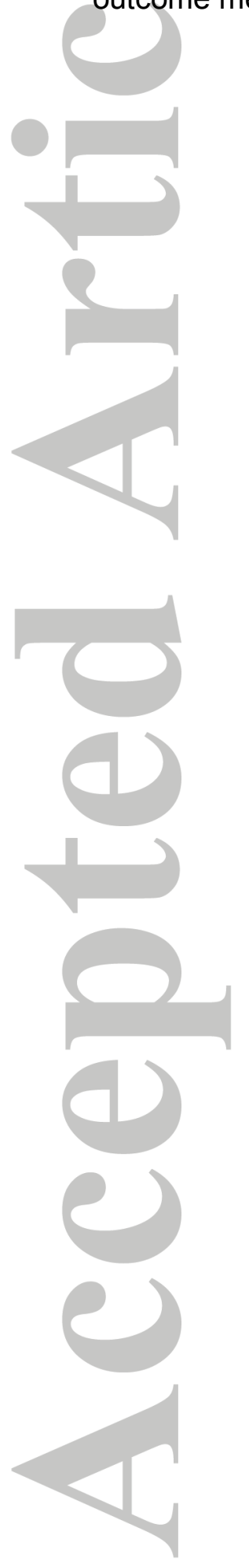

John Wiley \& Sons, Inc. 


\section{Significance and Innovations}

- SSc-related digital lesions are often used as end points in clinical trials outcome measures that can objectively quantify these lesions are badly needed.

- Digital planimetry has been used to make reliable, objective measurements on photographs of SSc-related digital lesions for the first time.

- Digital planimetry requires no specialist imaging equipment beyond a digital camera, and provides a simple method of quantifying and monitoring SScrelated digital lesions.

- SSc-related digital lesions can be reliably measured with software using both ellipse and free-hand-drawn shaped regions of interest. 


\section{Introduction}

Systemic sclerosis (SSc) is a complex connective tissue disorder characterised by widespread tissue fibrosis, activation of the immune system and ischaemia. Although SSc is a clinically heterogeneous disorder, almost all patients have skin involvement (scleroderma) [1]. Patients with SSc can also develop a spectrum of digital ischaemic lesions, including digital ulcers (DUs) and digital pitting scars (2). Up to $50 \%$ of patients with SSc report a history of DUs [3,4], and approximately $10 \%$ have DUs at any given moment [5]. DUs tend to occur at the tips or extensor aspects of fingers, are often extremely painful, and have a negative impact on hand function [2,5]. Patients with SSc-related DUs are likely to have increased anxiety levels and disability than those without [6]. Furthermore, DUs commonly become infected and may progress to osteomyelitis, gangrene and septicaemia without appropriate intervention [7]. A clear record of DU status (e.g. healing and progression) is essential in managing DUs effectively, to help clinicians to decide whether or not patients with DUs are benefitting from treatment pathways, thus optimising resources $[8,9]$. The need for a reliable, objective method for recording DU healing and progression is also highly pertinent in research, where DUs are often used as the primary end point in SSc clinical trials $[10,11]$.

There are currently no national guidelines or standardised methods for recording and assessing DUs in the clinical environment. Additionally, there is no 'gold standard' for measuring either DU or wound area in research: commonly used methods for tracking SSc-related DUs include measuring the widest diameter or modelling the DU as an ellipse $[10,12]$. Currently, most clinical trials do not measure DUs, instead subjectively assessing and then counting the number of new and healed DUs. Interrater reliability for defining DUs is fair to moderate at best (inter-rater kappa $=0.46$ - 
0.53) $[12,13]$, possibly reflecting the subjectivity of the assessments used. One possible objective option is planimetry - the preferred technique in other wound healing studies. This involves tracing the wound outline onto an overlayed transparent acetate film. The wound area can then (manually or digitally) be derived from the film $[14,15]$. Planimetry is, however, relatively time-consuming and can be difficult on small or awkwardly-placed wounds. For these reasons it has been little used in the tracking of DU healing. Alternatively, there have been numerous studies which have shown that photographic techniques for measuring wound area are reliable/precise when compared to planimetry $[14,16]$.

Photographic tracking of DUs is a possible objective assessment method of SScrelated DU status. The main aim of this study was to define and test a protocol for measuring dimensions of digital lesions/DUs in photographs. Specific objectives were firstly to compare two software-based methods for measuring DU surface area in photographs ((1) fitting an ellipse shape to the ulcer boundary, and (2) free-hand drawing round the DU border) and secondly to assess intra-/inter-rater reliability of each of these two methods, and reliability of photgraphic calibration.

\section{Methods and Materials}

\section{Participants}

Photographs of 107 finger lesions were collected from two ongoing SSc-related DU studies (one of which is reported in [17]). All 'finger lesions' were accepted into the study. All patients $(n=36)$ provided signed, informed consent. Patients were $78 \%$ female $(n=28)$, had a median age (range) of 56 (21-89) years, and had a median disease duration (range) of 10 (1-57) years. Nineteen patients (53\%) had the limited cutaneous subtype of SSc, and $16(44 \%)$ diffuse cutaneous. One patient had an 
'SSc-spectrum disorder' and no clear disease date of first non-RP feature. Some patients and/or lesions were photographed more than once: three patients were photographed twice, one patient was photographed three times, while 4 lesions were imaged on two or more occasions. Images were collected over the course of a 6 month period. Patients who had lesions imaged more than once had 1-2 weeks between any 2 images.

\section{Photograph Acquisition}

All photographs were taken by a trained medical photographer with a $105 \mathrm{~mm}$ micro lens using either a Nikon D300 or D700 camera (magnifications of 1:3 or 1:2 for the two cameras respectively). Consistent illumination was ensured using two subject lights and two rear lights with reflectors used at the photographer's discretion. A $1 \mathrm{~cm}$ adhesive calibration scale was placed in each photograph (see Figure 1A). A standard grey reference card was photographed immediately prior to the clinical photograph to allow white balancing of the collected images. The original 2:3 image ratio was kept after in-camera cropping and the final image was uploaded as a jpeg to a secure server.

\section{DU software measurement}

All images were analysed through a custom software interface written in MATLAB (MATLAB and Statistics Toolbox Release 2012a, The MathWorks Inc., Natick, Massachusetts). The software methods used are simple and could therefore be reimplemented locally by any interested party. DU photographs were loaded in batches of ten and the following steps were followed for each image:

1. The images were calibrated by measuring the distance in pixels along the $1 \mathrm{~cm}$ calibration scale, and then using this value to calculate the pixel size for 
the whole image (Figure 1A). The mean of five repetitions of this process on each image was taken to reduce the possibility of error.

2. An ellipse-shaped region of interest (ROI) was overlaid onto the image and positioned and scaled to best encompass the DU boundary.

3. A free hand ROI was drawn using the mouse as input.

For each image, the calibration values and the areas/dimensions generated were saved for further statistical analysis. Furthermore, the ROI shapes were also saved to allow investigation of the overlap and correlation between their respective areas.

\section{Defining lesion area}

The digital lesion boundary was defined as the clear interface between the lesion and the peri-lesion area. Where uncertainty existed due to multiple, concentric boundaries being visible; the centre-most of these was used. Areas of erythema or blanching were not included since these are usually considered to be part of the perilesion. Where more than one DU was visible in an image the largest contiguous lesion was chosen.

\section{Ellipse ROI drawing and placement}

The ellipse ROls were placed by the assessor defining the end points of the longest diameter across the DU, thus defining the long axis of the ellipse. The perpendicular, short axis was then adjusted using a sliding software control until the best fit of the ellipse to the DU was achieved (Figure 1B).

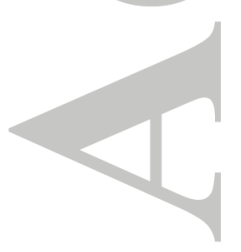




\section{Free hand ROI drawing and placement}

A free hand ROI was created by clicking and dragging the cursor around the lesion boundary (Figure 1C). The ROI area was calculated as the number of pixels contained within the boundary.

\section{Reliability testing and statistical analysis}

Three assessors analysed the images independently. The first assessor repeated the process five times in all (for intra-rater reliability), producing a total of 535 ellipse and 535 free hand area measurements on the 107 images. The other two assessors performed the analysis once, producing 107 ellipse and 107 free hand area measurements each. Inter-rater reliability was investigated by comparing the mean of the first assessor's measurements with those taken by the other two assessors. The 535 ellipse and 535 free hand areas measured by the first assessor were used to investigate the agreement between the two area measures. Additionally, the ellipse/free hand ROIs were compared for each image to give a percentage overlap, i.e. the area which the ellipse and free hand shape have in common (Figure 1D). Intra and inter-rater reliability for all measures was assessed using the intraclass correlation (ICC). Agreement between ellipse area and free hand area was analysed using a Bland-Altman plot.

All ICCs were calculated using SPSS software (IBM SPSS Statistics for Windows, Version 22.0, IBM Corp), all other statistical analyses were performed in GraphPad Prism (version 6.04 for Windows, GraphPad Software) and Stata (Release 13, StataCorp.).

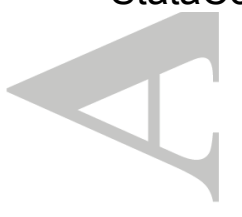




\section{Results}

\section{Calibration}

The ICC for the five calibration measurements per image was 0.99 (95\% confidence interval $[\mathrm{Cl}] 0.99$ to 1.00$)$, showing excellent intra-rater reliability in calibration measurements.

\section{Reliability of ellipse and free hand ROIs}

Intra-rater reliability estimates $(95 \% \mathrm{Cl})$ for ellipse and free hand ROls were 0.97 (0.96 to 0.98 ) and 0.98 (0.97 to 0.98$)$, respectively. Similarly, inter-rater reliability estimates $(95 \% \mathrm{Cl})$ for ellipse and free hand ROls were $0.77(0.70$ to 0.83$)$ and 0.76 (0.69 to 0.82 ), respectively. One lesion image was excluded due to the inability of the observers to define a clear border (the image was a necrotic area involving the whole finger tip).

\section{Absolute measurements and ROI agreement}

The mean (SD) ellipse ROI area taken using all assessors' observations was 18.7 (20.2) $\mathrm{mm}^{2}$. In a similar way, the mean (SD) free hand ROI area was 17.6 (19.3) $\mathrm{mm}^{2}$. Figure 2 shows the Bland Altman plot comparing ellipse and free hand areas; data plotted are the exponentiated differences (ellipse minus free hand area) in logtransformed means of the two techniques calculated using the five measurements taken by the first assessor, plotted against the paired averages of the means. This plot describes a slight bias with an ellipse:free hand area ratio of 1.11 (i.e. ellipse areas are, on average, approximately $11 \%$ larger than free hand areas). However, the agreement between both area measures (first assessor, 5 measurements) as assessed by ICC $(95 \% \mathrm{Cl})$ was high: 0.98 (0.97 to 0.99). 


\section{Discussion}

We have demonstrated a method of digital planimetry for assessing photographs of SSc-related digital lesions. We have shown appropriate calibration of images using length scales within the image, and custom computer software, can allow assessment of lesion area within these photographs. To our knowledge this is the first study to test the intra- and inter-rater agreement using a software-based approach of two methods (ellipse and free hand) for measuring 'finger lesion' area. The intra- and inter-rater agreement for these methods was very high for both the ellipse (0.97 and 0.77 respectively) and free hand (0.98 and 0.76 respectively) measurements. Manual ellipse area measurements (using digital callipers) have previously been assessed by Baron et al as part of an attempt to develop consensus agreement on the definition of DUs in SSc [12]. These investigators reported only moderate intra-rater $(0.57)$ and inter-rater $(0.48)$ reliability for their method, which suggests there is a potential benefit of using a software-based approach.

We found a very high agreement (ICC of 0.98) when comparing ellipse and free hand areas, suggesting that the two estimation methods can be used interchangeably. The ellipse area measurements are slightly larger $(+11 \%)$ than the free hand, probably a result of fitting the ellipse to the largest lesion dimension and its orthogonal component resulting in a shape whose boundaries tend to partially lie outside the border of the lesion, although there are can sometimes be portions of the free hand ROI which lie outside of the ellipse. The good area size agreement between the two ROI types is likely explained by these effects mostly cancelling each other out (Figure 1D). The limits of agreement from the Bland Altman plot (Figure 2) suggest that we can expect ellipse ROls to be between $14 \%$ smaller and $44 \%$ larger than free hand ROls. 
It is possible that the two ROI methods have good agreement in part due to the fairly regular shapes (circular/oval/ellipsoidal) presented by typical digital lesions in patients with SSc, allowing the ellipse ROI to perform similarly to the free-hand ROI. If generalising this digital planimetry technique to other, less regularly-shaped wound types it will be necessary to test both ROI types to confirm, or otherwise, continuing interchangeability. It should be noted that measurement using either of the two ROI types takes a similar amount of time (approx. 10 seconds per lesion), and that there are no other differences between them regarding implementation or use.

In conclusion, these two digital planimetry methods for SSc-related digital lesions should now be compared against other commonly-used measurement methods (callipers and traditional planimetry), against other novel imaging techniques for quantifying digital lesions, such as laser speckle contrast analysis (LASCA) [18], and against subjective assessments of DU status, to validate their further use. There is scope for these methods to incorporate machine learning, where features in images are automatically detected and measured using a computer algorithm. Future studies should incorporate colour analysis of the bed of the DU and surface curvature of the body into lesion area calculations, as these are important components of the DU construct. We believe that the measurement method described here has high applicability, with potential for use in both a research setting, and within clinical care.

\section{Acknowledgements}

We are grateful to the Clinical Photography department at Salford Royal NHS Foundation Trust for taking the photographs used in this work. 


\section{References}

1. Krieg T, Takehara K. Skin disease: a cardinal feature of systemic sclerosis. Rheumatology 2009; 48 Suppl 3:iii14-8.

2. Amanzi L, Braschi F, Fiori G, Galluccio F, Miniati I, Guiducci S, et al. Digital ulcers in scleroderma: staging, characteristics and sub-setting through observation of 1614 digital lesions. Rheumatology 2010; 49:1374-82.

3. Hachulla E, Clerson P, Launay D, Lambert M, Morell-Dubois S, Queyrel V, et al. Natural history of ischemic digital ulcers in systemic sclerosis: single-center retrospective longitudinal study. J Rheumatol 2007; 34:2423-30.

4. Tiev KP, Diot E, Clerson P, Dupuis-Siméon F, Hachulla E, Hatron P, et al. Clinical features of scleroderma patients with or without prior or current ischemic digital ulcers: post-hoc analysis of a nationwide multicenter cohort (ItinérAIR-Sclérodermie). J Rheumatol 2009; 36:1470-6.

5. Ennis H, Vail A, Wragg E, Taylor A, Moore T, Murray A, et al. A prospective study of systemic sclerosis-related digital ulcers: prevalence, location, and functional impact. Scand J Rheumatol 2013; 42:483-6.

6. Bérezné A, Seror R, Morell-Dubois S, De Menthon M, Fois E, Dzeing-Ella C, et al. Impact of systemic sclerosis on occupational and professional activity with attention to patients with digital ulcers. Arthritis Care Res 2011; 63:277-85.

7. Galluccio F, Matucci-Cerinic M. Two faces of the same coin: Raynaud phenomenon and digital ulcers in systemic sclerosis. Autoimmun Rev 2011; $10(5): 241-3$.

8. Hughes M, Ong VH, Anderson ME, Hall F, Moinzadeh P, Griffiths B, et al. Consensus best practice pathway of the UK Scleroderma Study Group: digital 
vasculopathy in systemic sclerosis. Rheumatol 2015; 54:2015:2024.

9. NHS England clinical comissioning policy: Sildenafil and bosentan for the treatment of digital ulceration in systemic sclerosis. Website: https://www.engage.england.nhs.uk/consultation/specialised-services-

policies/user uploads/bosntn-sildnfl-syst-sclerosis-pol.pdf, accessed April 2017.

10. Korn JH, Mayes M, Matucci Cerinic M, Rainisio M, Pope J, Hachulla E, et al. Digital ulcers in systemic sclerosis: prevention by treatment with bosentan, an oral endothelin receptor antagonist. Arthritis Rheum 2004; 50:3985-93.

11. Wigley FM, Wise RA, Seibold JR, McCloskey DA, Kujala G, Medsger TA, et al. Intravenous iloprost treatment of Raynaud's phenomenon and ischemic ulcers secondary to systemic sclerosis. J Rheumatol 1992; 19:1407-14.

12. Baron M, Chung L, Gyger G, Hummers L, Khanna D, Mayes MD, et al. Consensus opinion of a North American Working Group regarding the classification of digital ulcers in systemic sclerosis. Clin Rheumatol 2013; $33: 207-14$

13. Herrick AL, Roberts C, Tracey A, Silman A, Anderson M, Goodfield M, et al. Lack of agreement between rheumatologists in defining digital ulceration in systemic sclerosis. Arthritis Rheum 2009; 60:878-82.

14. Thawer HA, Houghton PE, Woodbury MG, Keast D, Campbell K. A comparison of computer-assisted and manual wound size measurement. Ostomy Wound Manage 2002; 48:46-53.

15. Zulian F, Meneghesso D, Grisan E, Vittadello F, Fortina AB, Pigozzi B, et al. A new computerized method for the assessment of skin lesions in localized 
scleroderma. Rheumatology 2007; 46:856-60.

16. Rogers LC, Bevilacqua NJ, Armstrong DG, Andros G. Digital planimetry results in more accurate wound measurements: a comparison to standard ruler measurements. J Diabetes Sci Technol 2010; 4:799-802.

17. Hughes M, Roberts C, Tracey A, Dinsdale G, Murray A, Herrick AL. Does the clinical context improve the reliability of rheumatologists grading digital ulcers in systemic sclerosis? Arthrit Care Res 2016; 68:1340-5. doi:10.1002/acr.22833

18. Ruaro B, Sulli A, Smith V, Paolino S, Pizzorni C, Cutolo M. Short-term followup of digital ulcers by laser speckle contrast analysis in systemic sclerosis patients. Microvasc Res 2015; 101:82-85. 

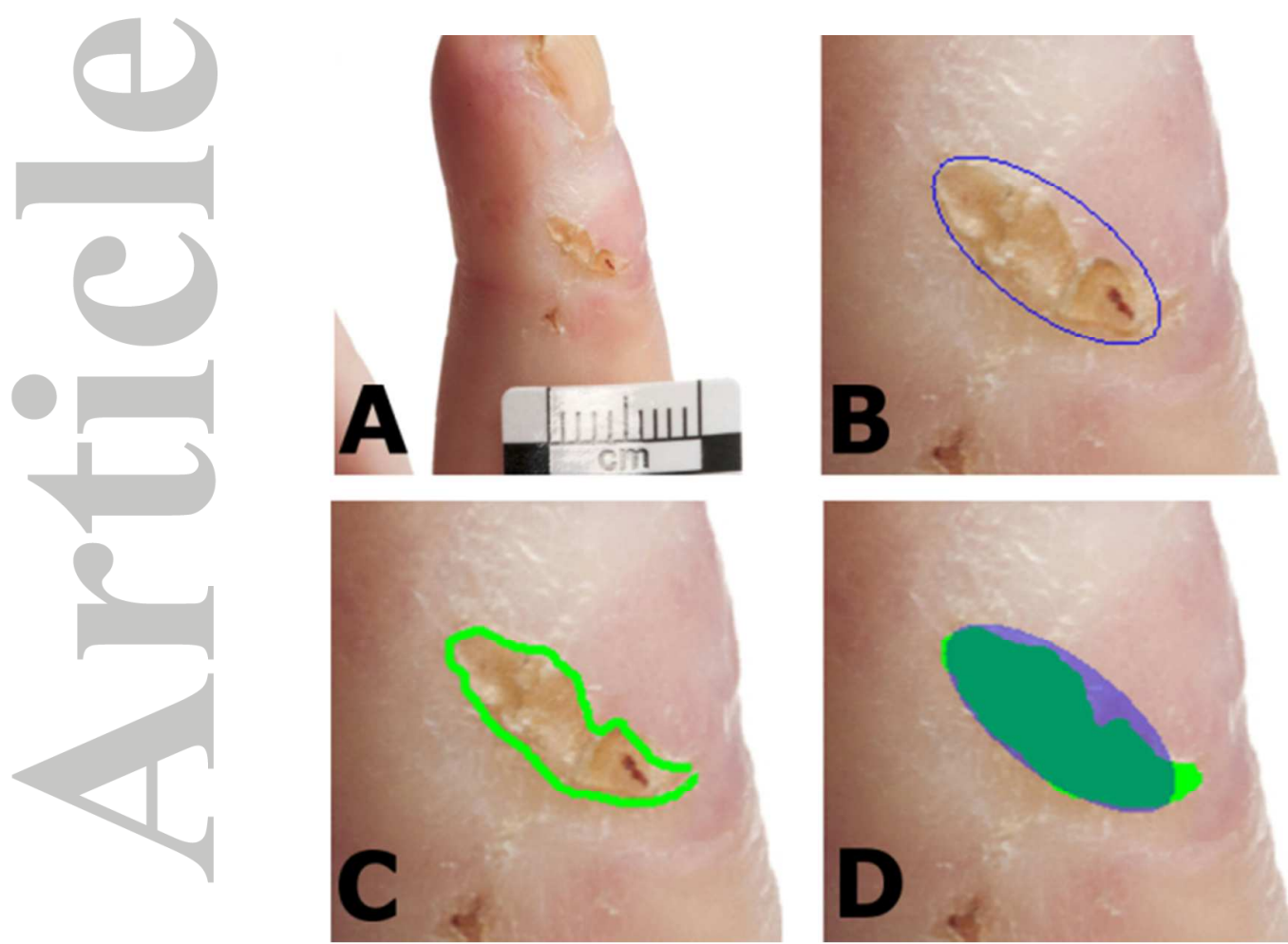

Figure 1. (A) Exemplar lesion photograph showing typical placement of the calibration scale. (B) Ellipse ROI fitted to the lesion in Fig. 1(A). (C) Free hand ROI fitted to the lesion in Fig. 1(A). (D) Overlap of ROI areas - dark green: common area to both ellipse and free hand ROls; purple: area unique to ellipse ROI; light green: area unique to free hand ROI. 


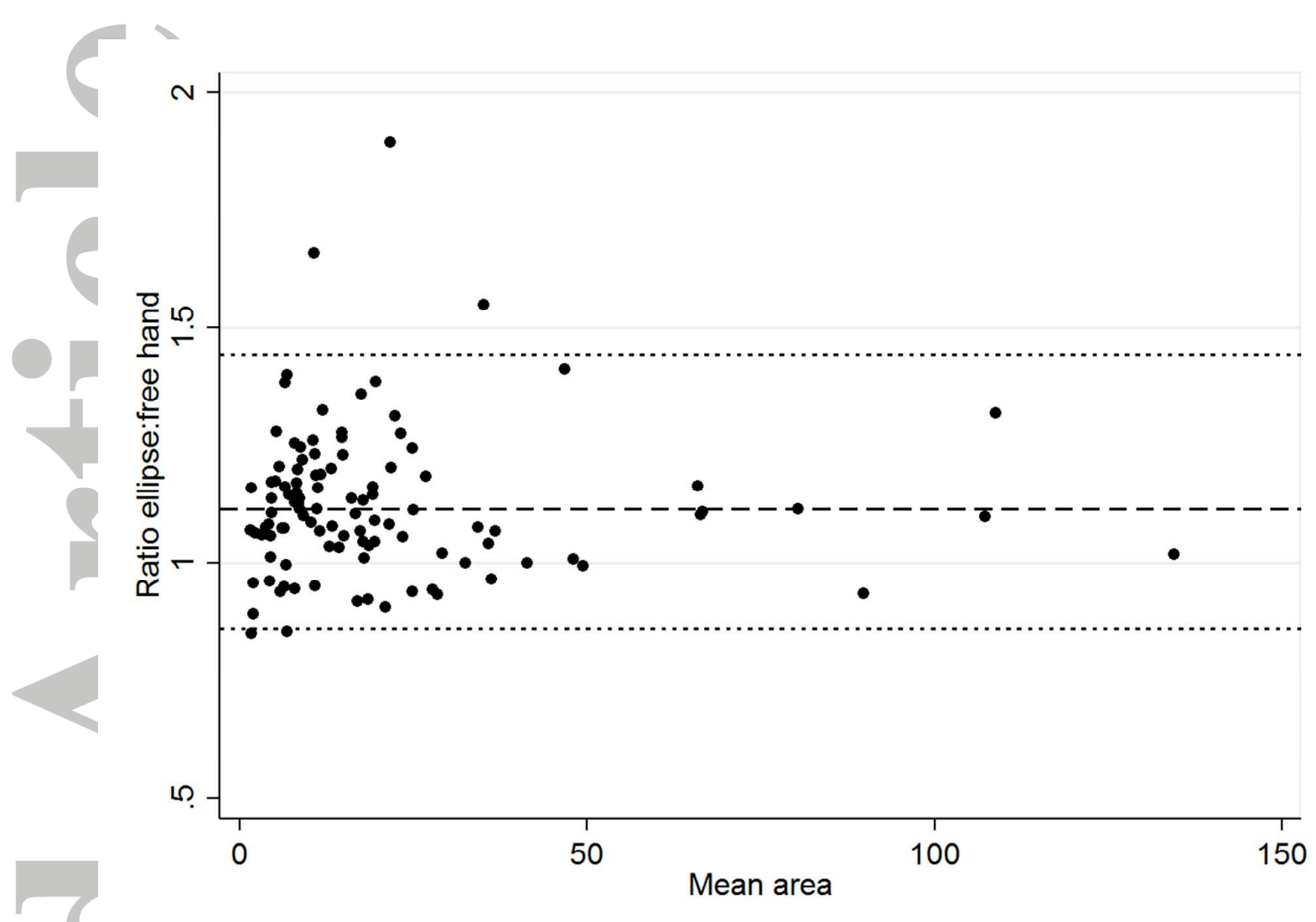

Figure 2. Bland Altman plot comparing ellipse and free hand ROI areas. Data were log-transformed, differences calculated, and then back-transformed before plotting. Data plotted are derived from the respective means of the five measurements taken by the first assessor only. The dashed line is the mean ellipse:free hand ratio (1.11), while dotted lines are the limits of agreement (lower: 0.86, upper 1.44). 